\title{
IMPLANTAÇÃO DA COLETA SELETIVA EM JANUÁRIA-MG: AVALIAÇÃO PRÉVIA DO INTERESSE DOS MORADORES DE BAIRRO RESIDENCIAL
}

\author{
Nathylla Bianca Costa e Nunes ${ }^{1}$ \\ Rodrigo Nogueira Martins ${ }^{2}$ \\ Valéria Silva Rodrigues ${ }^{3}$ \\ Danilo Pereira Ribeiro 4
}

\begin{abstract}
Resumo: Esse trabalho foi realizado com o objetivo de avaliar previamente o nível de consciência ambiental, o interesse e participação na coleta seletiva, caso seja implantada, dos moradores de área residencial, do bairro Jussara, no município de Januária/MG. O estudo foi baseado em aplicação de questionário, em 80 residências, com perguntas objetivas, onde se verificou que $65 \%$ dos entrevistados estão muito preocupados com os impactos ocasionados pelos seus resíduos sólidos. Também se constatou como é feita a disposição final dos resíduos, inclusive do óleo usado, e o interesse dos mesmos em fazer a separação dos materiais recicláveis se implementada a coleta seletiva. Assim, a proposta de implementação da coleta seletiva parece viável ao município, pois a maioria dos moradores se mostraram preocupados e interessados em participar e separar os materiais recicláveis. E houve consenso em relação ao melhor horário do dia e frequência de coleta do material reciclável.
\end{abstract}

Palavras-chave: Resíduos sólidos; Consciência ambiental; Aterro sanitário.

\footnotetext{
${ }^{1}$ Engenharia Agrícola e Ambiental/Instituto Federal do Norte de Minas Gerais - IFNMG Campus Januária, Brasil. E-mail: nathylla@yahoo.com.br.

2 Engenharia Agrícola e Ambiental/Instituto Federal do Norte de Minas Gerais - IFNMG Campus Januária, Brasil. E-mail: rodrigonmartins@hotmail.com.

${ }^{3}$ Engenharia Agrícola e Ambiental/Instituto Federal do Norte de Minas Gerais - IFNMG Campus Januária, Brasil. E-mail: valeriarodrigues00@yahoo.com.br.

${ }^{4}$ DSC. Engenharia Agrícola/Instituto Federal do Norte de Minas Gerais - IFNMG Campus Januária, Brasil. E-mail: danilo.ribeiro@ifnmg.edu.br.
} 